\title{
HEAT TRANSFER ENHANCEMENT THROUGH DIFFERENT CIRCULAR DIAMETRICAL DIMPLE SURFACE UNDER FORCED CONVECTION -AN EXPERIMENTAL APPROACH
}

\author{
M.A.Dafedar ${ }^{1}$, Mujtabalayeeq $\mathrm{I}^{\mathbf{2}}$, Mohemmed TaherM ${ }^{3}$, MohammadIdress urf Shahid $\mathrm{I}^{\mathbf{4}}$ \\ ${ }^{1}$ Assistant Prof, ${ }^{2,3}$ UG Scholar Department of Mechanical Engineering, SECAB Institute of engineering and Technology, \\ KARANATAKA, INDIA, msadafedar@gmail.com,layeeq2008@gmail.com,taher619@gmail.com \\ ${ }^{4} U G$ Scholar, Department of Mechanical Engineering, B.L.D.E.A'S Dr. P.G.Halakatti College of Engineering and \\ Technology, KARANATAKA, INDIA, shahid28486@gmail.com
}

\begin{abstract}
The prime objective of present work is to study experimentally the heat transfer enhancement through different circular diametrical dimple surfaces in longitudinal and lateral directions. In this paper horizontal rectangular plates of Stainless Steel and Galvanised Iron with different circular diametrical dimples (like $11 \mathrm{~mm}, 14 \mathrm{~mm}$ ) for in-line arrangements were studied in forced convection with varying laminar external flow condition. The various parameters considered for study are Reynolds Number, Nusselt number, Prandtl Number, Co-efficient of Friction, Heat transfer coefficient and heat transfer rate for a constant Prandtl number (0.698) It has been found that the heat transfer coefficient and heat transfer rate increases for various dimple surfaces as compared to plane surface. It has been also found that the heat transfer coefficient and heat transfer rate increases along longitudinal direction as compared to lateral direction. And it is seen that heat transfer rate is maximum for larger diameter (14mm) of dimple. For circular dimples, heat transfer enhancements (relative to a flat plate) were observed for Reynolds number range from 350 to 550.
\end{abstract}

Index Terms: Dimple plates, Forced Convection, Heat transfer Enhancement

\section{INTRODUCTION}

The importance of heat transfer enhancement has gained greater significance in such areas as microelectronic cooling, especially in central processing units, macro and micro scale heat exchangers, gas turbine internal airfoil cooling, fuel elements of nuclear power plants, and bio medical devices. A tremendous amount of effort has been devoted to developing new methods to increase heat transfer from fined surface to the surrounding flowing fluid. Rib turbulators, an array of pin fins, and dimples have been employed for this purpose. A variety of experimental, analytical and Numerical research work has been carried out on augmentation of heat transfer. . Over the past couple of years the focus on using dimples on surface for intensifying the heat transfer has been documented by many researchers. A variety of Experimental, analytical and Numerical research work has been carried out on augmentation of heat transfer. Kuethe [1] was the first suggest the use of dimple surface for heat transfer enhancement. Surface dimples are expected to promote turbulent mixing in the flow and enhance the heat transfer, as they behave as a vortex generator. Sandeep S. Kore \& Narayan K.Sane [2] was carried out experiment to study heat transfer and friction coefficient by dimpled surface with the aspect ratio of rectangular channel is kept 4:1 and Reynolds number based on hydraulic diameter is varied from 10000 to 40000 . They were observed that at all Reynolds number as depth increases from 0.2 to 0.3 , the number and thermal performance increases and then after when depth increase from 0.3 to 0.4 normalized Nusselt number and thermal performance decreases. $\mathrm{Ph}$. Grenard ; et al[3] presents the numerical study performed with the CEDRE code, developed at ONERA, to predict heat transfer on a dimpled surface placed on one wall of a rectangular channel. Various models of turbulence are tested on three basic configurations. Nikolai Kornev [4] Vortex structures and heat transfer enhancement mechanism in a turbulent flow over a staggered dimple array in a narrow channel have been investigated using Large Eddy Simulation (LES). Shinichi Kogusu et al [5] Heat transfer coefficients were measured in a channel with one side dimpled surface. The sphere type dimples were fabricated, and the diameter (D) and the depth of dimple was $16 \mathrm{~mm}$ and $4 \mathrm{~mm}$, respectively. Two channel heights of about $0.6 \mathrm{D}$ and $1.2 \mathrm{D}$, two dimple configurations were tested. Johann Turnow [6] studied the flow structure within a two-dimensional spherical cavity on a flat surface, numerically and experimentally. They observed that the recirculation zone formed inside the cavity slightly reciprocate around itself. Mahmood and Ligrani [7] analyzed experimentally the influence of dimple aspect ratio, temperature ratio, Reynolds number and flow structures in a dimpled channel at Reynolds number varying from 600 to 
11,000 and $\mathrm{H} / \mathrm{D}$ ratio varying as $0.20,0.25,0.5$ and 1.00 . The results showed that the vortex pairs which were periodically shed from the dimples become stronger as channel height decreases with respect to the imprint diameter.

\section{EXPERIMENTAL PROCEDURE}

The experimental set up for present study is shown. The set up mainly consist of heater with capacity of 200 watts, Dimmer stat, Digital temperature, voltmeter, and Ammeter with J type Thermocouple, Valve for air regulation, Orifice meter, U tube manometer, Air blower The test plates were placed on heater in a rectangular duct closed from both the sides. An inlet and outlet ports are provided for air inlet and outlet. A constant heat is supplied through dimmer stat to heater. Air flows parallel to the dimpled test surface. The plate heater is fixed at the bottom of the test plate, and was connected to power socket through dimmer stat. Dimmer stat readings were varied to give the required heat input to the test plate. Only top dimpled surface of the test plate was exposed to the air stream from which the convective heat transfer to the air stream takes place. After reaching a steady state the inlet and outlet temperature of air with surface temperature of plate and dimples were measured with the help of thermocouple. Similarly for varying air flow rate $(100 \%, 75 \%, 50 \%$ air flow rate ) the corresponding reading where taken.

\subsection{Test plates}

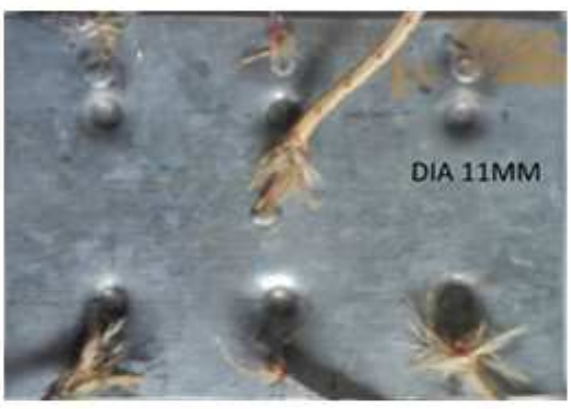

$135 \mathrm{MM}$

Circular dimple $11 \mathrm{~mm}$ diameter

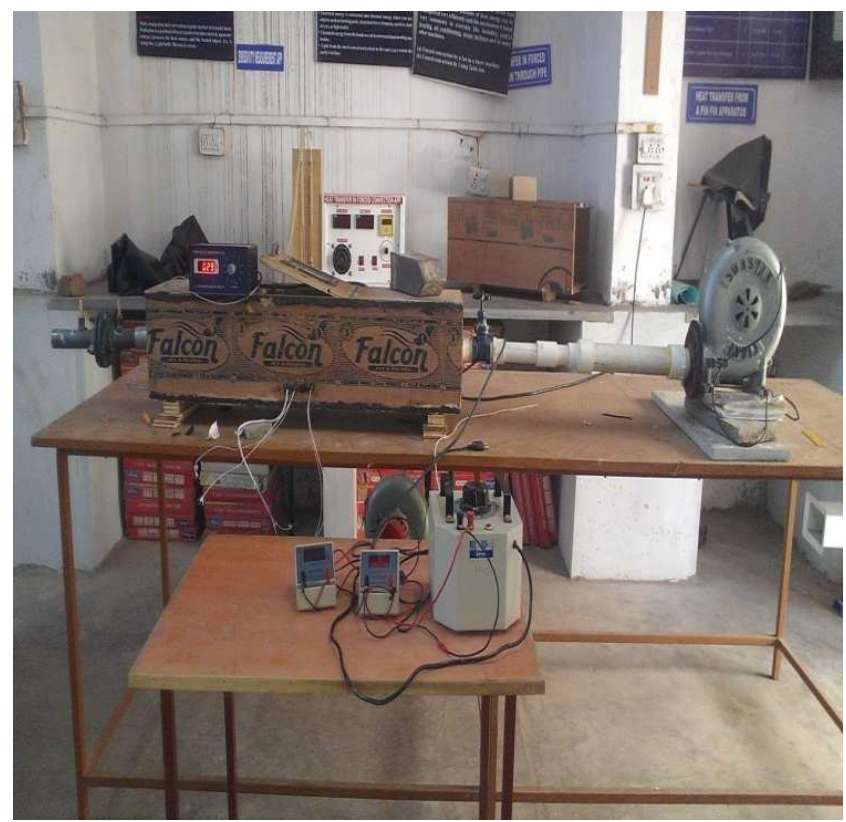

Fig 1: Experimental Setup
$95 \mathrm{MM}$

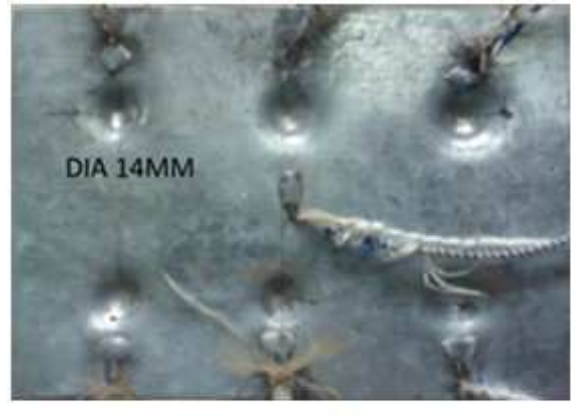

$135 \mathrm{MM}$
$95 \mathrm{MM}$

Circular dimple $14 \mathrm{~mm}$ diameter

Fig-2: Different circular diameterical dimpled surface

The two different circular diameterical dimples were used for present study. Figure shows different dimple surfaces on rectangular plate of size $95 \mathrm{~mm} \times 135 \mathrm{~mm}$. circular dimple of dia $11 \mathrm{~mm}$ and $14 \mathrm{~mm}$ were used.

The depth of all the dimples is kept constant and six dimples on each plate with inline arrangement were used as show above.

\subsection{Data Reduction}

The study is carried out under forced convection for external laminar flow condition. Steady state value of the plate and air temperatures in the channel, at

A) Reynolds number

$$
R e=\frac{V L}{v}
$$

$\mathrm{V}=$ is the mean velocity of the air inside the duct $\mathrm{m} / \mathrm{s}$ 
$\mathrm{L}=$ is the length of the test plate in meter

$V=$ Kinematic Viscosity at film temp in $\mathrm{m}^{2} / \mathrm{s}$.

B) Nussult number

$$
N_{u}=0.664 * R_{e}^{0.5} * P_{r}^{0.3333}
$$

$\operatorname{Re}=$ Reynolds number

$\operatorname{Pr}=$ Prandtl Number

C) Heat Transfer Co-efficient $\mathrm{h}_{\mathrm{a}}=\frac{N u * \text { Kair }}{L}$

$\mathrm{K}_{\mathrm{air}}=$ Thermal Conductivity of air at film temp

D) Rate of heat transfer

$\mathrm{Q}_{\mathrm{a}}=\mathrm{h}_{\mathrm{a}} \mathrm{A}\left(\mathrm{T}_{\mathrm{s}}-\mathrm{T}_{\infty}\right)$

$\mathrm{Q}_{\mathrm{a}}=$ Average heat transfer rate in Watts

The Orifice consist of Orifice plate of $4 \mathrm{~mm}$ hollow diameter and whose co-efficient of discharge is 0.64

\section{RESULTS AND DISCUSSION}

\subsection{RESULTS FOR G.I PLATE}

Table 1= Result for plane G.I plate

\begin{tabular}{|l|l|l|l|}
\hline $\begin{array}{l}\text { AIR } \\
\text { RATE }\end{array}$ & $\begin{array}{l}100 \% \\
\text { FLOW } \\
\text { RATE }\end{array}$ & $\begin{array}{l}75 \% \\
\text { FLOW } \\
\text { RATE }\end{array}$ & $\begin{array}{l}\text { FLOW } \\
\text { RATE }\end{array}$ \\
\hline $\mathrm{Re}$ & 538.2222 & 459.7859 & 369.4777 \\
\hline $\mathrm{C} f$ & 0.05724 & 0.06193 & 0.06908 \\
\hline $\mathrm{Nu}$ & 13.6691 & 12.6325 & 11.3242 \\
\hline $\mathrm{Pr}$ & 0.69843 & 0.69843 & 0.69843 \\
\hline $\mathrm{w} / \mathrm{m}^{2 \circ} \mathrm{C}$ & 2.8300 & 2.6107 & 2.3445 \\
\hline $\mathrm{W}$ & & & \\
\hline & 0.8710 & 0.8203 & 0.7517 \\
\hline
\end{tabular}

Table 2=Result for $11 \mathrm{~mm}$ dimple dia

\begin{tabular}{|l|l|l|l|}
\hline $\begin{array}{l}\text { AIR } \\
\text { RATE }\end{array}$ & $\begin{array}{l}100 \% \\
\text { FLOW } \\
\text { RATE }\end{array}$ & $\begin{array}{l}75 \% \\
\text { FLOW } \\
\text { RATE }\end{array}$ & $\begin{array}{l}50 \% \\
\text { FLOW } \\
\text { RATE }\end{array}$ \\
\hline $\mathrm{Re}$ & 532.9477 & 457.0286 & 365.8480 \\
\hline $\mathrm{C} f$ & 0.05752 & 0.06211 & 0.6968 \\
\hline $\mathrm{Nu}$ & 13.59944 & 12.5935 & 11.26733 \\
\hline $\mathrm{Pr}$ & 0.69826 & 0.698255 & 0.698221 \\
\hline $\mathrm{w} / \mathrm{m}^{2 \circ} \mathrm{C}$ & 2.77680 & 2.6149 & 2.3456 \\
\hline $\mathrm{W}$ & 0.959120 & 0.94755 & 0.86628 \\
\hline
\end{tabular}

Table 3= Result for 14mm dimple dia

\begin{tabular}{|l|l|l|l|}
\hline $\begin{array}{l}\text { AIR FLOW } \\
\text { RATE }\end{array}$ & $\begin{array}{l}100 \% \\
\text { FLOW } \\
\text { RATE }\end{array}$ & $\begin{array}{l}75 \% \text { FLOW } \\
\text { RATE }\end{array}$ & $\begin{array}{l}\text { 50\% FLOW } \\
\text { RATE }\end{array}$ \\
\hline $\mathrm{Re}$ & 531.3274 & 455.2630 & 364.2045 \\
\hline $\mathrm{Cf}$ & 0.0576125 & 0.062239 & 0.069586 \\
\hline $\mathrm{Nu}$ & 13.57967 & 12.56861388 & 11.2427 \\
\hline $\mathrm{Pr}$ & 0.698175 & 0.69815 & 0.6981334 \\
\hline $\mathrm{w} / \mathrm{m}^{2}{ }^{\circ} \mathrm{C}$ & 2.83035 & 2.565859 & 2.345695 \\
& & & \\
\hline $\mathrm{W}$ & 1.03121 & 0.952481 & 0.90046 \\
\hline
\end{tabular}




\section{2 RESULTS FOR STAINLESS STEEL PLATES}

Table 4= Result for plane SS plate

\begin{tabular}{|l|l|l|l|}
\hline $\begin{array}{l}\text { AIR } \\
\text { RATE }\end{array}$ & $\begin{array}{l}100 \% \\
\text { FLOW } \\
\text { RATE }\end{array}$ & $\begin{array}{l}75 \% \\
\text { FLOW } \\
\text { RATE }\end{array}$ & $\begin{array}{l}50 \% \\
\text { FLOW } \\
\text { RATE }\end{array}$ \\
\hline $\mathrm{Re}$ & 535.2080 & 464.8100 & 369.3255 \\
\hline $\mathrm{C} f$ & 0.05742 & 0.06159 & 0.06910 \\
\hline $\mathrm{Nu}$ & 13.6292 & 12.7032 & 11.3226 \\
\hline $\mathrm{Pr}$ & 0.69841 & 0.6985 & 0.6934 \\
\hline $\mathrm{w} / m^{2 \circ} \mathrm{C}$ & 2.8227 & 2.6206 & 2.3441 \\
& & & \\
\hline $\mathrm{W}$ & 0.9130 & 0.8403 & 0.81106 \\
\hline
\end{tabular}

Table 5= Result for $11 \mathrm{~mm}$ dimple dia

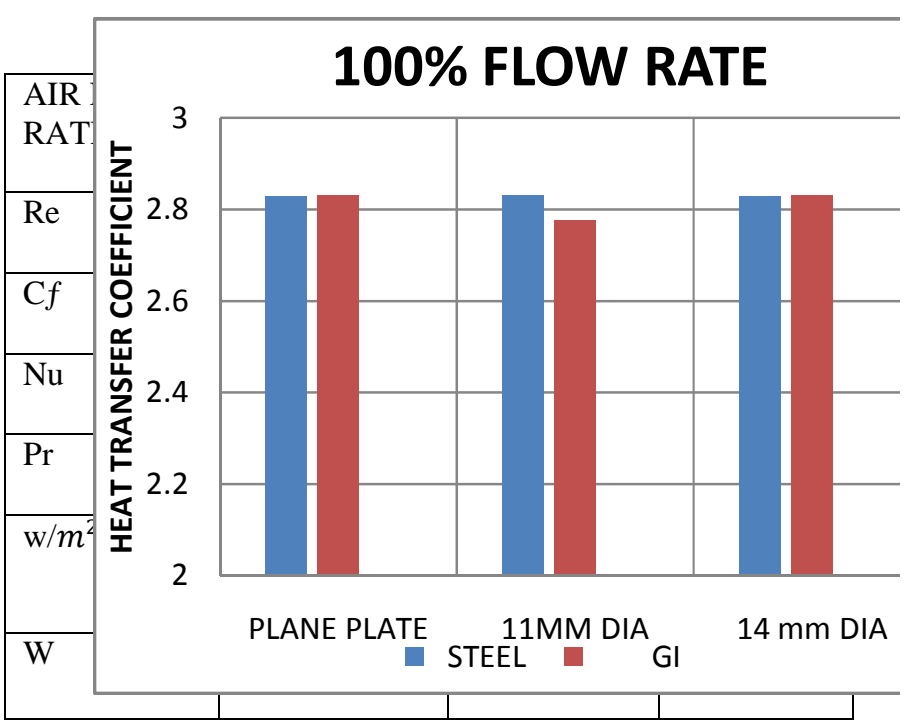

\begin{tabular}{|l|l|l|l|}
\hline $\begin{array}{l}\text { AIR } \\
\text { RAOW }\end{array}$ & $\begin{array}{l}100 \% \\
\text { FLOW } \\
\text { RATE }\end{array}$ & $\begin{array}{l}75 \% \\
\text { FLOW } \\
\text { RATE }\end{array}$ & $\begin{array}{l}\text { FLOW } \\
\text { RATE }\end{array}$ \\
\hline $\mathrm{Re}$ & 533.8050 & 459.8146 & 367.8046 \\
\hline $\mathrm{C} f$ & 0.05747 & 0.06193 & 0.06924 \\
\hline $\mathrm{Nu}$ & 13.6103 & 12.6339 & 11.2991 \\
\hline $\mathrm{Pr}$ & 0.69825 & 0.69835 & 0.69831 \\
\hline $\mathrm{w} / m^{2 \circ} \mathrm{C}$ & 2.8308 & 2.6212 & 2.3467 \\
\hline $\mathrm{W}$ & 0.9416 & 0.8799 & 0.8067 \\
\hline
\end{tabular}

From the figure 4,5,6 we can see the graph plotted again the heat transfer coefficient vs different dimpled diameter is show. As we can from the figures the heat transfer coefficient decreases with decrease in Air flow rate.

As we can see from figure 4 heat transfer coefficient is maximum as compared with the figure 5 and 6 and maximum in case of steel.

Fig 4

If we compare the figure 5 with figure 4 the heat transfer coefficient decreases but the heat transfer coefficient is greater in steel as it is compared with GI plate. 


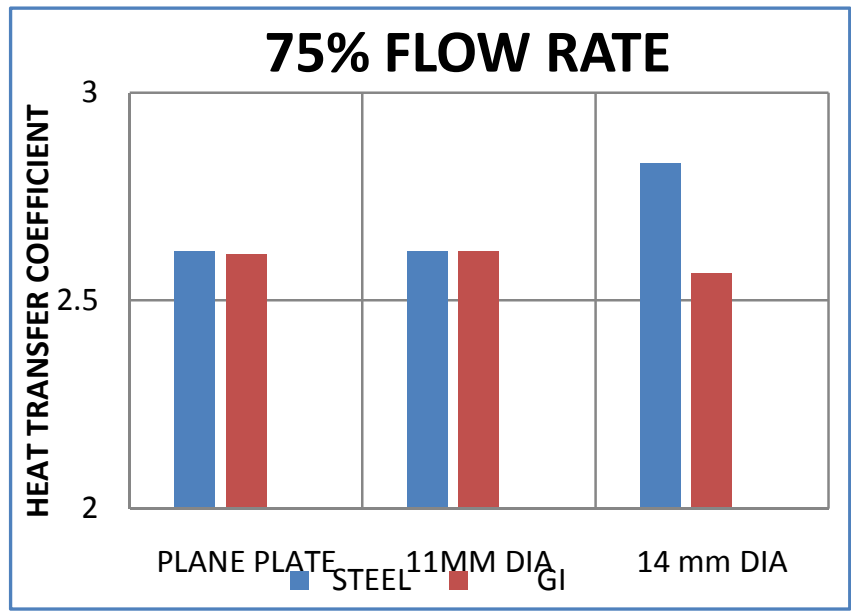

Fig 5

From the figure 6 we can notice that heat taransfer rate is minimum at $50 \%$ flow rate because due to decrease in air flow rate heat transfer rate decreases.

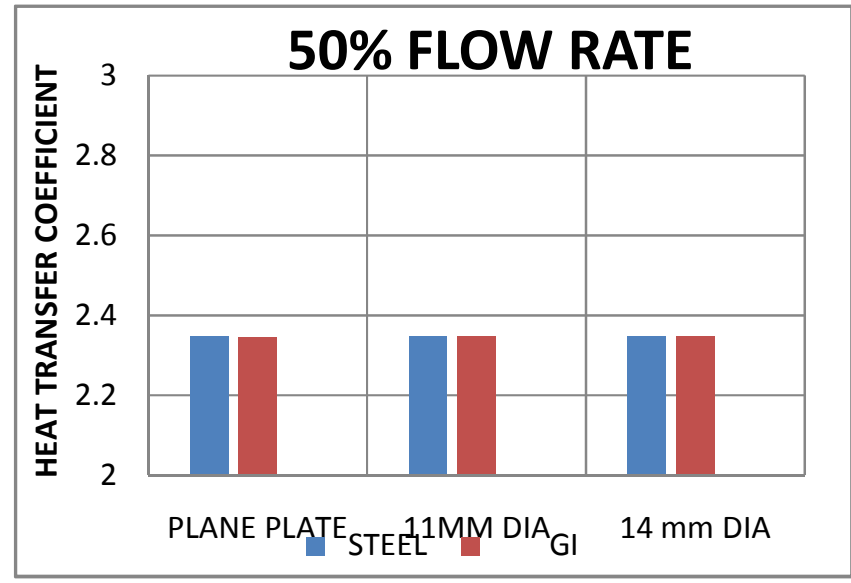

Fig 6

Heat transfer coefficient is observed in the range of 2-3 $\mathrm{w} / \mathrm{m}^{2}{ }^{\circ} \mathrm{C}$

From the figure $7,8,9$ we can see the graph plotted against coefficient of friction vs different dimpled diameter. As we can see from the above figure that co-efficient of friction increases with decrease in air flow rate

From the figure 7 we can see that the coefficient of friction is low as it is compared with the figure 8 and 9 . Co-efficient of friction increases with decrease in air flow rate.

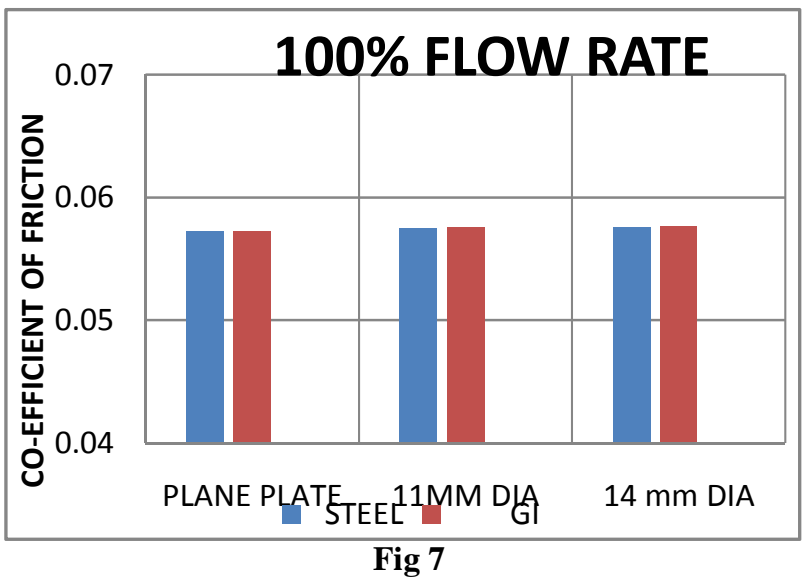

From figure 8 we can see that co-efficient of friction increases if it is compared with the figure 7 . Here the co-efficient of friction is maximum in case of G.I due to its surface roughness.

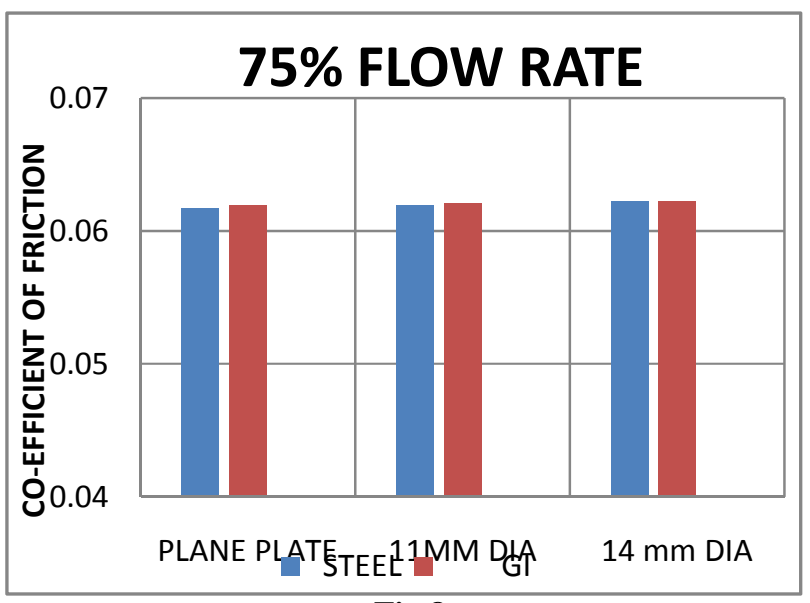

Fig 8

From the figure 9 we can see the maximum co-efficient friction. Due to decrease in air flow rate co-efficient of friction increase and is greater in case of G.I as it is compared with Steel.

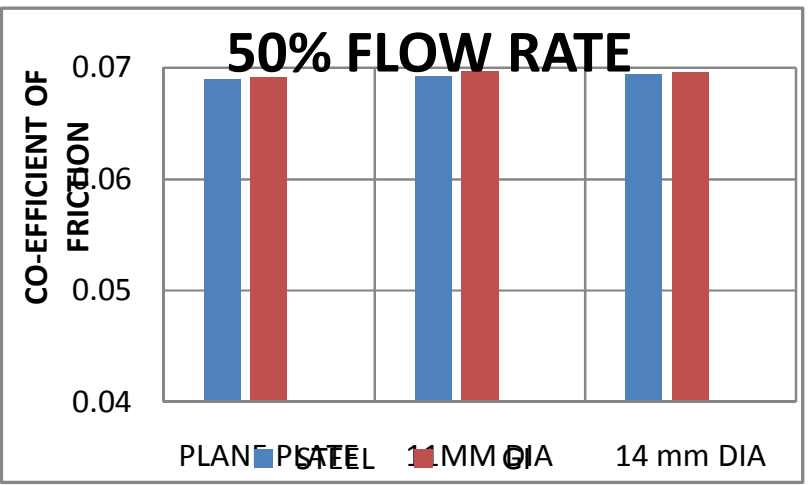


Fig 9

Co-efficient of friction is observed in the range of $0.055-0.07$ $\mathrm{C} f$

From the fig $10,11,12$ we can see the graph plotted again Nusselt number VS different dimpled diameter is shown. As we can that the Nusselt number decreases with decrease in Air flow rate.

From 10 we can see that the nusselt is at its highest peak as it is compared with the othere two graph.

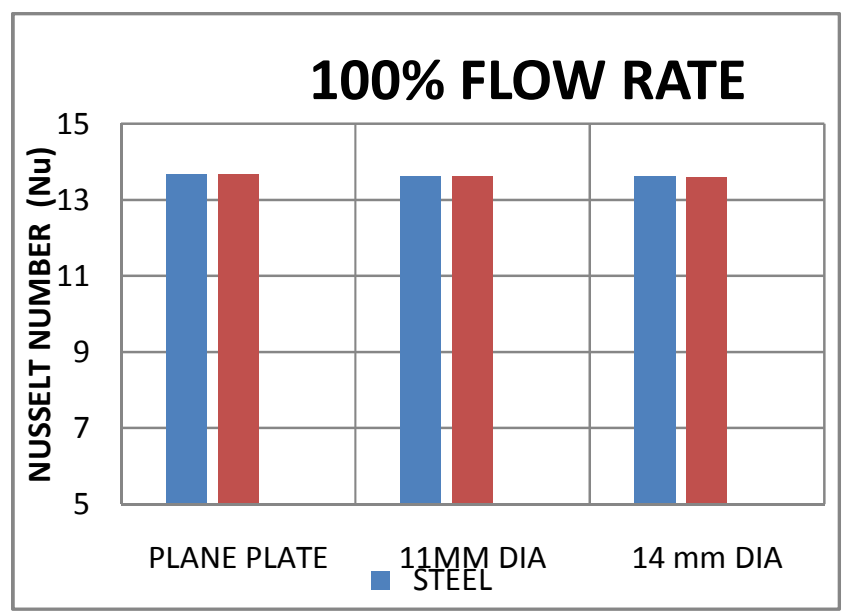

Fig 10

From the figure 11 we can see that the nusselt number decreases with decrease in Air flow rate as it is compared with the figure 10 .

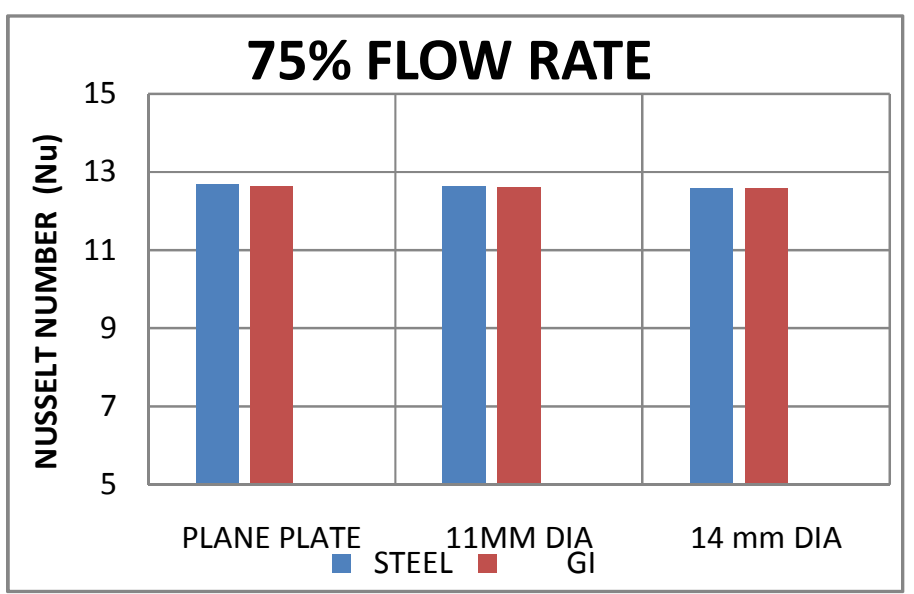

Fig 11

From figure 1`2 we can see that the Nusselt number is minimum as it is compared with the figure 10 and 11

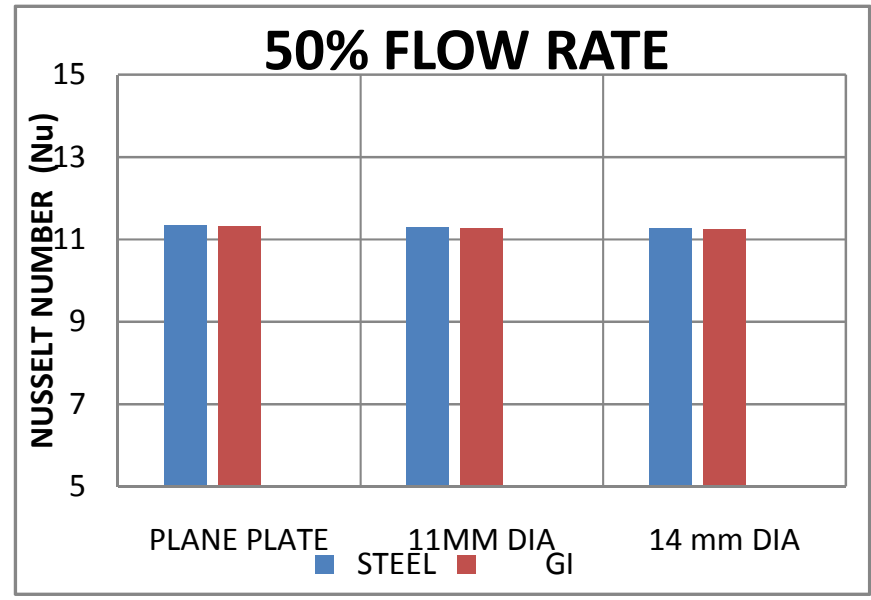

Fig 12

The Nusselt number obtained is in between the range of 11-14 $\mathrm{Nu}$.

\section{CONCLUSIONS}

From the present study the following conclusion were made:

- It is found that the heat transfer rate is more for dimpled surfaced plate when compared with plane plates (both for Stainless Steel and G.I) irrespective of their diameters.

- It is concluded that the maximum heat transfer rate will takes place in largest diameter of the circular dimpled surface.

- It is found that the Nusselt number decreases with decrease in air flow rate.

- The Nusselt number is maximum for Stainless Steel as it is compared with G.I

- Nusselt number is directly proportional to the Heat transfer rate hence we can say that heat transfer rate is maximum in G.I as it is compared with the steel.

- Co-efficient of friction is inversely proportional to Reynolds number and the Co-efficient of friction increases with reduction in air flow rate and co-efficient of frction is greater for G.I.

- The heat transfer coefficient is more for G.I as it is compared with Stainless Steel

- As it also concluded that heat transfer rate $(\mathrm{Q})$ is maximum in G.I plates as compared with Stainless steel

- Heat transfer rate is directly proportional to Reynolds number, as the Reynolds number increases heat transfer rate also increases.

- The Reynolds number obtained is in between the range of 350 to 550 . 
- Heat transfer co-efficient is maximum in G.I for both Steel and G.I at bigger diameter of dimpled surface i.e at $11 \mathrm{~mm}$ dia.

Finally we can conclude that rate if heat transfer increases with increase in diameter of the dimple and is maximum for largest dimple diameter

\section{ACKNOWELEGEMENTS}

We would like to thank our principal and management for their support and help towards this work.

\section{REFERENCES}

[1] Kuethe A. M., (1971). Boundary Layer Control of Flow Separation and Heat Exchange, US. Patent No. 3,578,264

[2] Sandeep S. Kore \& Narayan K.Sane, (August 2011). International Journal of Engineering Science and Technology (IJEST), Vol. 3 No. 8

[3] Tafti et al. (1999). Investigation of Heat Transfer Enhancement using Vortex Generators. M.E. Dissertation work. Shivaji University Kolhapur. 1998-99

[4] Nikolai Kornev. Flow structures and heat transfer on dimpled surfaces (http://www.tsfp7.org/papers/2B4P.pdf).

[5]Shinichi Kogusu et al (2007). Rapid Generation of Surface Dimples Using End Milling. June 4.

[6]. Johann Turnow, Valery Zhdanov, Egon Hassel FLOW STRUCTURES AND HEAT TRANSFER ON DIMPLED SURFACES.

[7]. Mohammad A. Elyyan, (nd). Heat Transfer Augmentation Surfaces Using Modified Dimples/Protrusions

\section{BIOGRAPHIES}

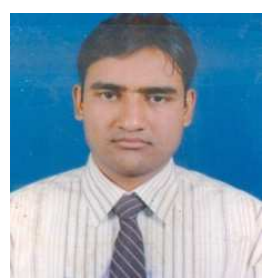

M.A.Dafedar has done his M.Tech in Production Technology from Basveshwar Engineering college Bagalkot in 2006. $\mathrm{He}$ is working as an Assistant Prof and HOD in mechanical engineering Department of SECAB IET BIJAPUR. $\mathrm{He}$ has got an experience of 8 years in teaching and 1 year industry. He has guided many UG Projects. Currently he is pursuing his $\mathrm{PhD}$ (Heat Transfer) from Visvesvaraya Technological University Belgaum. His area of interest is Fluid mechanics, Heat transfer, Operations research and Machine drawing

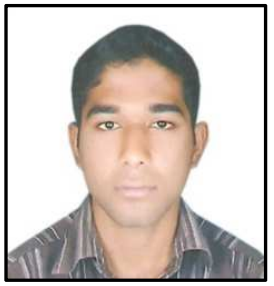

Mujtabalayeeq S Inamdar is pursuing his B.E. in Mechanical Engineering from Secab institute of engineering and technology Bijapur his subject of interest is Heat Transfer, Thermodynamics, Automative Engineering.

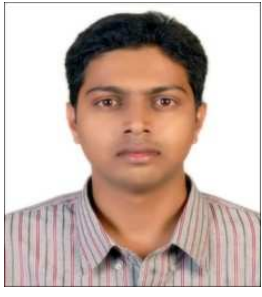

Mohemmed Taher Mujawar is pursuing his B.E. in Mechanical Engineering from Secab institute of engineering and technology Bijapur his subject of interest is Heat Transfer, Thermodynamics and Fluide Flow.

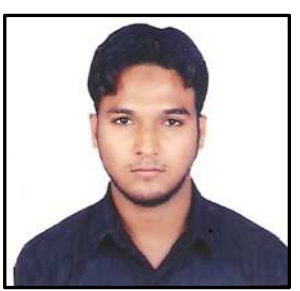

MohammadIdress urf Shahid Inamdar has completed his B.E. in Mechanical Engineering from B.L.D.E.A'S Dr. P.G.Halakatti College of Engineering and Technology Bijapur his subject of interest is Heat Transfer, Thermodynamics and Control engineering. 